this plane; and let the motion be referred to $\mathrm{SX}, \mathrm{SZ}$, and a line perpendicular to them as axes. Now in consequence of the proper motions of the sun and the two stars, these lines will not constitute a system of axes which are either fixed in space or which move parallel to themselves; consequently, if these lines be taken as axes of reference the observed (or calculated) value of the motion of rotation of any object will necessarily be relative to these axes, and its absolute value cannot be determined without ascertaining the angular motion of the axes of reference. But since the two stars have been specially selected from amongst those whose proper motions have eluded detection, the angular motions of the axes will be so small compared with ordinary standards that the error caused by neglecting them will lie within the limits of experimental error. If, for example, we were to endeavour to calculate by the above method, or some similar one, the absolute angular velocities of the hands of a clock, or of a fly-wheel, the value which we should thereby obtain would be as exact as the existing state of mechanical and instrumental appliances admits.

A series of observations extending over several thousand years might of course reveal a proper motion of any two selected stars; but in the case of angular motions whose periods do not extend much beyond a century, the above method leads to results which are for most practical purposes exact.

I am therefore disposed to think that all motions of rotation of which our senses are capable of taking cognisance are relative; but with the exception of certain astronomical motions of very long periods, the absolute value of any motion of rutation which can be observed may be accurately determined within the limits of experimental error.

Fledborough Hall, Holyport, Berks.

The gist of Mr. Love's long letter, on pp. I98--9, seems to be that since the specification of a force or a motion depends upon the choice of axes, therefore the force or motion itself is similarly dependent. A slight extension of the same principle would make a velocity-say the velocity of light-depend upon whether it was to be expressed in miles per second or in centimetres perhour; and no extension at all is necessary to make it depend on whether it is referred to Groombridge 1830, or to some more quiescent body, if indeed the term quiescence may be allowed henceforth to have any meaning.

Tycho Brahé is said to have held that there was only a question of language between the Copernican and the Ptolemaic systems; but, with the exception of a semi-ironical Church compromise attributed to Descartes, he has been unfortunate in not finding a disciple of importance until the present moment.

It appears now to be equally true to say that the earth rises to meet a stone, as to say that a stone falls to meet the earth; and considerations of energy are of no consequence !

I just want to add one word of my own on the subject, to the effect that whereas the position of a body in an infinite homogeneous stagnant ocean would be unmeaning and un specifiable, except by reference to boundaries or other bodies, yet it does not follow that the velocity of a body through such an ocean would be either unmeaning, unspecifiable, or undiscoverable by experiment. It may be replied that such motion would still be relative to something; and to that I say by all means, but it is not relative to other bodies such as are competent to fix position, which is what Mr. Love is contending for.

As to the other question, about absoluteness of rotation, I shall be much interested in seeing what Prof. Greenhill, and with him Profs. Mach and Karl Pearson, have to say on the point.

Liverpool, December 29, 1894. Oliver J. LODGE.

\section{The Quarrying of Granite in India.}

At Bangalore, in Southern India, the quarrying of granite slabs by means of wood fire has been brought to such perfection, that an account of the method may not be out of place. The rock is a grey gneissose granite of very irregular composition through unequal segregation of hornblende and the presence of numerouz felspathic veins. But it is otherwise very compact, and forms solid masses uninterrupted by cracks for several hundreds of feet. Only near the surface the rock is found split parallel to the surface. In one quarry there is thus, for instance, a 4-feet thick horizontal layer of rather weathered rock, underneath this another layer of fresh rock 3 feet thick; but below this the rock is entirely fresh, and not split. These layers are probably due to the variations of temperature, daily and seasonal.

The undisturbed rock is quarried by means of fire, and it is remarkable what large plates may be detached. I saw one plate of 60 feet greatest length, and 40 feet greatest width, and half a foot thickness. This thickness varied only one inch over the greater part of the area. The whole plate had been de. tached in one piece by means of wood-fire. Afterwards the plate was cut with blunt chisels into strips of $2 \frac{1}{2}$ feet width. So easily are these strips and slabs obtained, that it is quite common to see palisades of them used instead of boundary walls, and also to see them used as posts for huts, for telegraphs, and for railings and posts in gardens.

In one case, I observed the operation of burning over an area. A narrow line of wood-fire, perhaps 7 feet long, was gradually elongated, and at the same time moved forward over the tolerably even surface of solid rock. The line of fire was produced by dry logs of light wood, which were left burning in their position until strokes with a hammer indicated that the rock in front of the fire had become detached from the main mass underneath. The burning wood was then pushed forward a few inches, and left until the hammer again indicated that the slit had extended. Thus the fire was moved on, and at the same time the length of the line of fire was increased and made to be convex on the side of the fresh rock. The maximum length of the arc amounted to about 25 feet. It was only on this advancing line of fire that any heating took place, the portion which had been traversed being left to itself. This latter portion was covered with the ashes left by the wood, and with thin splinters which had been burst off. These splinters were only of about $\frac{1}{8}$ th inch thickness, and a few inches across. They were quite independent of the general splitting of the rock, which was all the time going on at a depth of about five inches from the surface. The burning lasted eight hours, and the line of fire advanced at the average rate of nearly 6 feet an hour. The area actually passed over by the line of fire was 460 square feet, but as the crack extended about 3 feet on either side beyond the fire, the area of the entire slab which was set free measured about 740 square feet. All this was done with, may be, about $15 \mathrm{cwt}$. of wood. Taking the average thickness of the stone at 5 inches, and its specific gravity as $2 \cdot 62$, the result is 30 lbs. of stone quarried with I lb. of wood.

The old quarries have sloping sides formed of steps left by each successively split plate, each new plate extending to within about 2 feet of the step left by the preceding plate. Many plates are taken out in an inclined position, and as the directions of inclination differ, it follows that the action of the fire is quite independent of the original surface of the rock, and also of the direction of lamination and of the numerous veins in the rock. The action of the fire is thus very similar to that action which produces dykes and faults ou a large scale, more or less independent of the nature of the rocks which are passed through.

The great uniformity of the thickness of the slabs formed by the above process is probably due to a regulating influence of the pre-existing crack. When the action of the fire is somewhat slower, it takes longer for the heat to penetrate down to the crack; when the action is quicker, there will be enough expansion produced in the upper layers, and the lower layers transmit the tension to the plane of the crack. Perhaps it will be possible some day to measure the temperature of the heated rock, when a certain agreement ought to be found between the tensile strength of the rock and the strain which the expansion by the heat produces in the so-far elastic rock.

Bangalore, December 19, 1894.

H. Warth.

\section{Storm Statistics at Bidston.}

THE Liverpool Observatory, erected at Bidston, on the Cheshire side of the estuary of the Mersey, stands on a slight eminence about 200 feet above the sea-level. The ascent is tolerably steep on each side except from the south, and with the Irish Sea on the north, and the rivers Mersey and Dee on the east and west sides respectively, there is nothing to obstruct or diminish the force of a passing storm. Self-recording anemometers of the Robinson and Osler types have been in position since 1867 , and it is from the records of these instruments that No. I 316 , vOL. $5 \mathrm{~J}]$ 